\title{
Enhanced Mechanical Properties and Isotropy of Mg-2Al-0.8Sn Alloy through Ca Addition
}

\author{
Yuan Miao ${ }^{1}$, Chao Wang ${ }^{2, *}$, Minghui Wang ${ }^{1}$, Hai Deng ${ }^{2}$, Pinkui Ma ${ }^{1}$ and Zhigang $\mathrm{Li}^{1,3, *(1)}$ \\ 1 Key Laboratory of Automotive Materials Ministry of Education, School of Material Science and Technology, \\ Jilin University, Changchun 130022, China; miaoyuan19@mails.jlu.edu.cn (Y.M.); minghui@jlu.edu.cn (M.W.); \\ mapk@jlu.edu.cn (P.M.) \\ 2 National Railway Vehicle Engineering Research Center, CRRC Changchun Railway Vehicles Co., Ltd., \\ Changchun 130062, China; denghai@cccar.com.cn \\ 3 State Key Laboratory of Automotive Simulation and Control, Jilin University, Changchun 130022, China \\ * Correspondence: wangchao.a@cccar.com.cn (C.W.); lzg@jlu.edu.cn (Z.L.)
}

Citation: Miao, Y.; Wang, C.; Wang, M.; Deng, H.; Ma, P.; Li, Z. Enhanced Mechanical Properties and Isotropy of Mg-2Al-0.8Sn Alloy through Ca Addition. Materials 2021, 14, 7557. https://doi.org/10.3390/ma14247557

Academic Editor: Halina Krawiec

Received: 12 November 2021

Accepted: 6 December 2021

Published: 9 December 2021

Publisher's Note: MDPI stays neutral with regard to jurisdictional claims in published maps and institutional affiliations.

Copyright: (c) 2021 by the authors. Licensee MDPI, Basel, Switzerland. This article is an open access article distributed under the terms and conditions of the Creative Commons Attribution (CC BY) license (https:// creativecommons.org/licenses/by/ $4.0 /)$.

\begin{abstract}
Calcium (Ca), with abundant and cheap reserves, is a potential element to facilitate the further application of $\mathrm{Mg}$-Al-Sn based alloys. Here, effects of $\mathrm{Ca}$ content on the microstructure and tensile properties of Mg-2.0Al-0.8Sn (wt.\%) alloys were systematically studied. The experimental results illustrated that the strength, ductility and isotropy of the alloys improved simultaneously with the increase of Ca content. The better ductility and isotropy could be contributed to the weakened texture via particle stimulation nucleation mechanism. The higher strength benefited from the combination of finer grains, more precipitates and residual dislocation density. Eventually, the Mg-2.0Al-0.8Sn-0.5Ca (wt.\%) alloy showed the best room-temperature balance of strength and ductility with a yield strength of $\sim 226.0 \mathrm{MPa}$, an ultimate tensile strength of $\sim 282.4 \mathrm{MPa}$ and a fracture elongation of $\sim 20.2 \%$, which has huge potential as an applicable low-cost high-performance magnesium alloy.
\end{abstract}

Keywords: Mg-Al-Sn alloy; Ca content; microstructure; anisotropy; tensile properties

\section{Introduction}

Magnesium $(\mathrm{Mg})$ and its alloys are hoped to tremendously reduce the mass of vehicles, allowing for better fuel efficiency and lower $\mathrm{CO}_{2}$ emissions [1-3]. However, they have poor mechanical properties at room temperature, which make for a huge challenge to wide application [4,5]. In the past few decades, people have made attempts to improve the strength and ductility via tailoring a $\mathrm{Mg}$ matrix with added alloying elements. The combined effect of adding $\mathrm{Al}$ and $\mathrm{Sn}$ has been reported to be of great help to ductility improvement by reducing the critical resolved shear stress (CRSS) difference between nonbasal slip and basal slip [6,7]. Hence, Mg-Al-Sn based (AT system) alloys have received much attention for their potentially excellent mechanical properties [8].

Aiming at further development and application of AT system alloys, it is worth trying to enhance the mechanical properties of the alloy through alloying. As an element with abundant and cheap reserves, Ca can randomize the texture of $\mathrm{Mg}$ alloys and form precipitates in Sn-containing $\mathrm{Mg}$ alloys because of its large electronegativity difference with Sn $[9,10]$. Moreover, $\mathrm{Ca}$ can also form thermally stable second phases, $\mathrm{Al}_{2} \mathrm{Ca}$ and $(\mathrm{Mg}$, $\mathrm{Al}_{2} \mathrm{Ca}$, with $\mathrm{Al}$, which are affiliated with the ratio of $\mathrm{Al}$ and $\mathrm{Ca}$ content $[11,12]$. Based on the above reasons, a great deal of studies have proved that Ca could boost the tensile properties of Mg-Sn alloy and $\mathrm{Mg}-\mathrm{Al}$ alloy. Pan et al. [13] designed a Mg-2Sn-2Ca alloy (wt.\%) with extraordinary yield strength (YS, $360 \mathrm{MPa}$ ), depending on its submicron matrix grains $(\sim 0.32 \mu \mathrm{m})$ and $\mathrm{Mg}_{2} \mathrm{Ca}$ precipitates. By adjusting the $\mathrm{Al} / \mathrm{Ca}$ ratio, $\mathrm{Li}$ [11] et al. designed a high-strength $\mathrm{Mg}-2.7 \mathrm{Al}-3.5 \mathrm{Ca}-0.4 \mathrm{Mn}$ (wt.\%) alloy with a ultra-high strength 
(YS: $438 \mathrm{MPa}$, ultimate tensile strength (UTS): $457 \mathrm{MPa}$ ), and a large-ductility Mg-4.4Al$1.1 \mathrm{Ca}-0.4 \mathrm{Mn}$ (wt.\%) alloy with an elongation (EL) of $29.9 \%$. Therefore, Ca is also a potential element to improve the mechanical properties of AT system alloys at room temperature.

However, the detailed roles of $\mathrm{Ca}$ content on the $\mathrm{Mg}$-Al-Sn alloys have not been clarified. Thus, in this study, Mg-Al-Sn alloys with different Ca content were cast, rolled and annealed. In addition, we primarily studied the tensile properties and asymmetry of as-annealed $\mathrm{Mg}-2.0 \mathrm{Al}-0.8 \mathrm{Sn}-\mathrm{xCa}(\mathrm{x}=0.0,0.3,0.5 \mathrm{wt} . \%)$ alloys. Such research will offer an essential basis for further boosting the mechanical properties and practical applications of AT system Mg alloys.

\section{Experimental Procedure}

In this work, Mg-2.0Al-0.8Sn-xCa (x=0, 0.3 and 0.5 wt. $\%)$ alloys were fabricated by melting pure $\mathrm{Mg}$ (99.90 wt.\%), pure Al (99.90 wt.\%), pure Sn (99.90 wt.\%) and Mg$25 \mathrm{Ca}(\mathrm{wt} . \%)$ in an electric furnace under a protective gas mixture of $99.5 \% \mathrm{CO}_{2}$ and $0.5 \%$ $\mathrm{SF}_{6}$ at $\sim 953 \mathrm{~K}$. After casting, ingots were extruded at $653-703 \mathrm{~K}$, with a ram speed of about $19.3-23.2 \mathrm{~mm} \mathrm{~s}^{-1}$ and an extrusion ratio of 28 . The extruded plates were then homogenized at $320^{\circ} \mathrm{C}, 420^{\circ} \mathrm{C}$ and $490^{\circ} \mathrm{C}$ for $2 \mathrm{~h}$, and hot-rolled at $350{ }^{\circ} \mathrm{C}$ from $\sim 5 \mathrm{~mm}$ to $\sim 0.9 \mathrm{~mm}$ by 4 passes, with $\sim 35 \%$ reduction per pass. During the whole rolling process, the rollers were maintained at $100{ }^{\circ} \mathrm{C}$ and the rolling samples were preserved for $6 \mathrm{~min}$ between passes. Afterward, the sheets were annealed at $275^{\circ} \mathrm{C}$ for $8 \mathrm{~min}$. The preparation process is shown in Figure 1a, and the nominal compositions of the prepared alloys are presented in Table 1. For simplicity, the as-annealed samples are denoted below as AT21, ATX2103 and ATX2105.
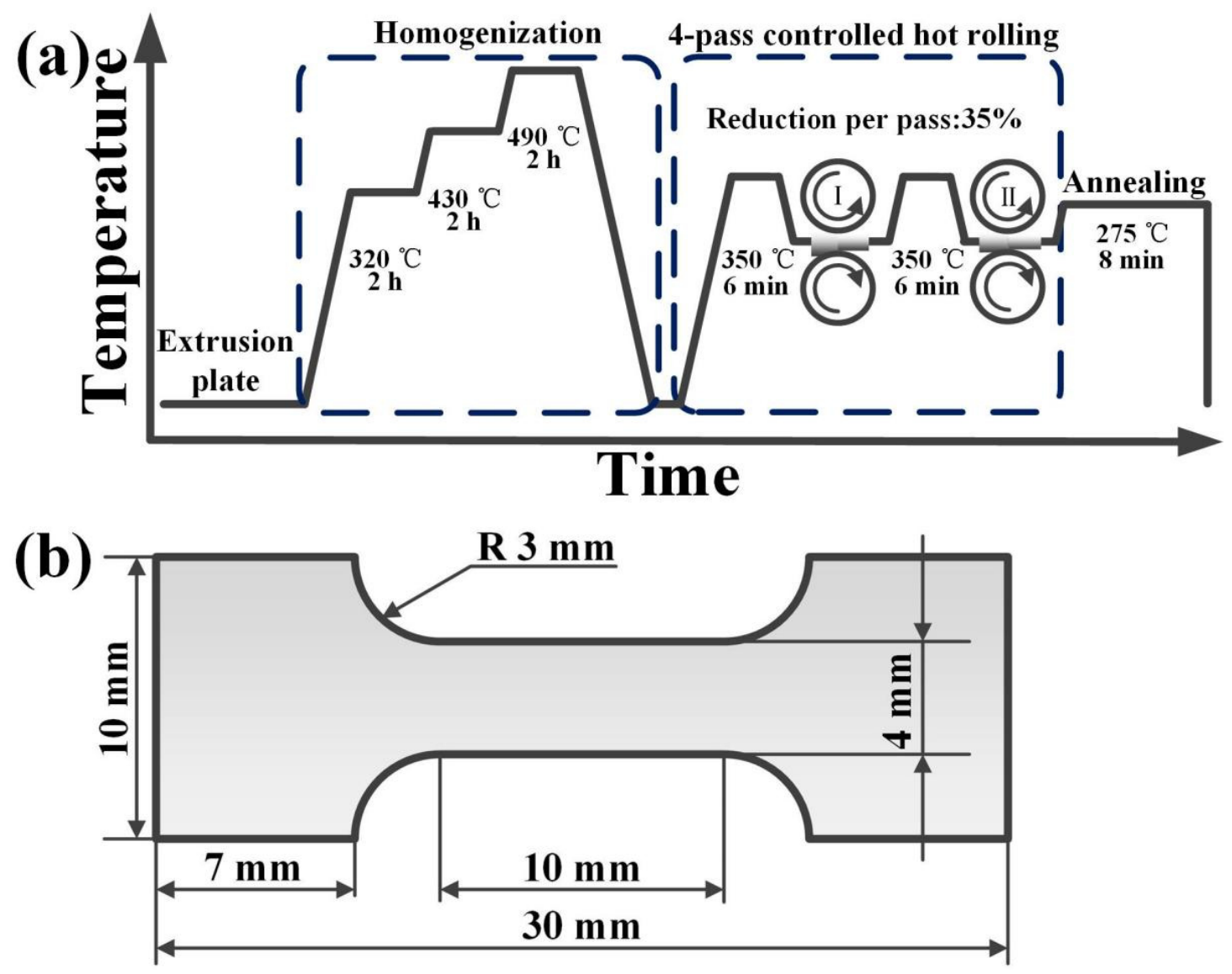

Figure 1. Schematic representation of (a) the preparation process and (b) the tensile test specimen. 
Table 1. Compositions of Mg-2.0Al-0.8Sn- $x \mathrm{Ca}(x=0.0,0.3$ and 0.5 wt. $\%)$ alloys.

\begin{tabular}{lcccc}
\hline \multirow{2}{*}{ Nominal Composition } & \multicolumn{4}{c}{ Measured Composition (wt.\%) } \\
\cline { 2 - 5 } & Al & Sn & Ca & Mg \\
\hline Mg-2.0Al-0.8Sn-0.0Ca & 1.96 & 0.77 & - & Bal. \\
Mg-2.0Al-0.8Sn-0.3Ca & 1.98 & 0.83 & 0.28 & Bal. \\
Mg-2.0Al-0.8Sn-0.5Ca & 2.01 & 0.79 & 0.51 & Bal. \\
\hline
\end{tabular}

The microstructure was characterized by a scanning electron microscope (SEM, VEGA 3 XMU, TECAN Czech, Mannedorf, Switzerland) equipped with energy dispersive spectrometer (EDS, OXFORD X-Max ${ }^{\mathrm{N}}$ AZtec) and electron backscatter diffraction (EBSD) detector (OXFORD NordlysNano AZtec). The analysis on phase constituents was performed by X-ray diffraction (XRD, Model D Max 2500PC Rigaku Tokyo, Japan). A transmission electron microscope (TEM, JEM-2100F, JEOL Ltd., Tokyo, Japan) was used to explore the information of nanoscale precipitates. TEM samples were thinned via mechanical grinding combined with ion-beam thinning.

All the dog-bone shaped tensile samples $(30 \mathrm{~mm} \times 10 \mathrm{~mm})$ were cut from the annealed sheets along rolling direction (RD) according to the cutting scheme shown in Figure $1 b$. Tensile tests were conducted through the universal test machine (SHIMADZU, Suzhou, China) under a strain rate of $1.0 \times 10^{-3} \mathrm{~s}^{-1}$. A minimum of five samples were tested to ensure reliability.

\section{Results and Discussion}

\subsection{Microstructural Characteristics}

The EBSD maps and grain size distribution maps of the as-homogenized samples are shown in Figure 2. The average grain sizes of as-homogenized AT21, ATX2103 and ATX2105 alloys are $\sim 30.1 \mu \mathrm{m}, \sim 29.0 \mu \mathrm{m}$ and $\sim 37.6 \mu \mathrm{m}$, respectively. All samples have large grain sizes and no regular changes in size, indicating that the initial structure has a negligible effect on the properties after rolling.
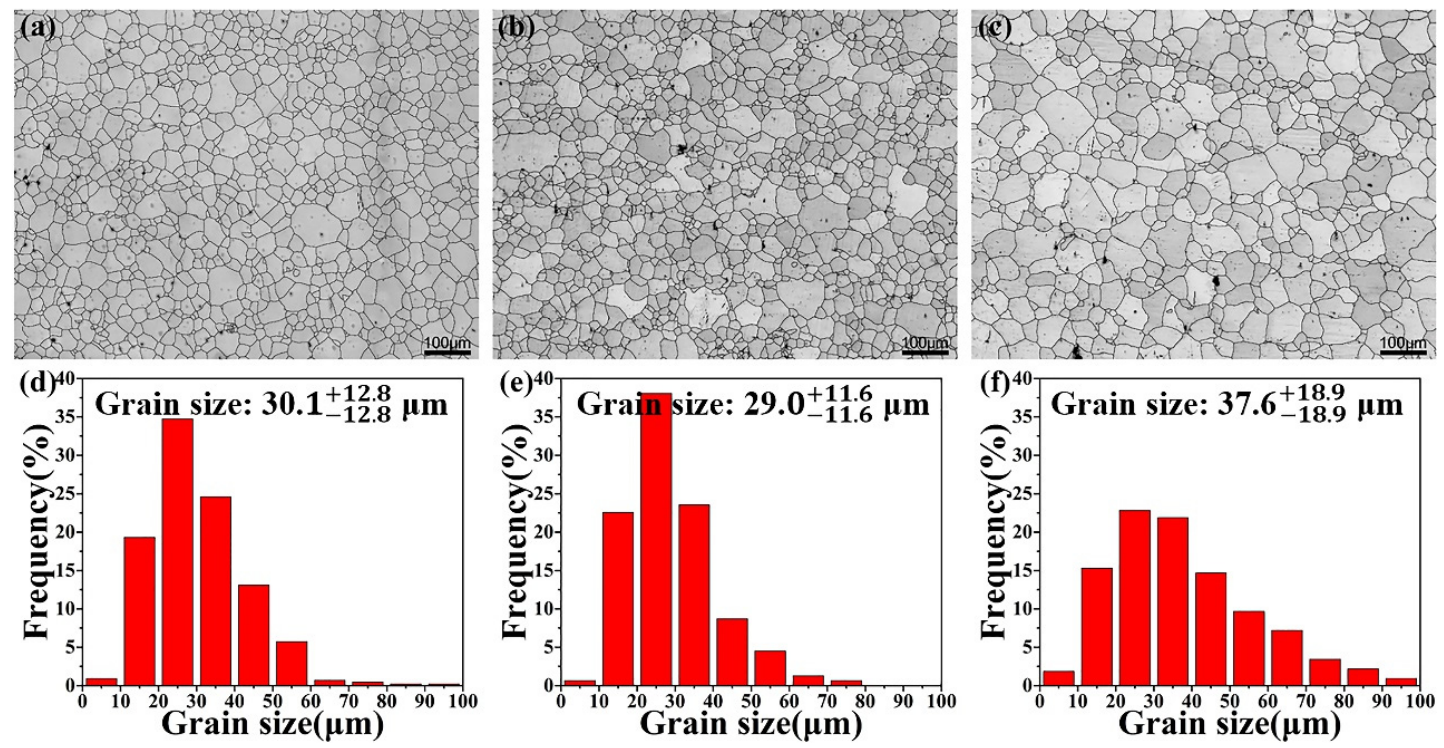

Figure 2. EBSD maps and corresponding grain size distributions of as-homogenized (a,d) AT21, (b,e) ATX2103 and (c,f) ATX2105 alloys.

Figure 3 presents the SEM and corresponding EDS results of as-annealed AT21, ATX2103 and ATX2105 alloys. With Ca content increasing from 0.3 to $0.5 \mathrm{wt} . \%$, there is an increasement in the area fraction of phases (varying from $\sim 3.74 \%$ to $4.41 \%$ ) but almost no second phase in the AT21 sample. Combining XRD maps with EDS micrographs 
(Figure 4), it can be concluded that massive irregular particles in ATX2103 and ATX2105 alloys are CaMgSn phase and the Al-containing particles are $(\mathrm{Mg}, \mathrm{Al})_{2} \mathrm{Ca}$. In addition, the relative intensities of diffraction peaks for the CaMgSn and $(\mathrm{Mg}, \mathrm{Al})_{2} \mathrm{Ca}$ phases increase with a rise in Ca content from 0.3 to $0.5 \mathrm{wt} . \%$, indicating that the volume fraction of them increases accordingly. To study the characteristics of precipitates, which are too small to be analyzed by SEM, TEM analysis was conducted on the annealed alloys (Figure 5). In ATX2105 alloy (Figure 5b), there exists more spherical fine precipitates than in ATX2103, displaying the volume fractions of precipitates of $\sim 1.40 \times 10^{-2}$ and $\sim 0.49 \times 10^{-2}$, respectively. The precipitation of ATX2103 alloy is basically spherical, while ATX2105 also has a rod-like phase. Through HRTEM analysis of particles A and B (Figure $5 c, d$ ), it is concluded that the spherical particles are $\mathrm{Mg}_{2} \mathrm{Ca}$ and the rod-shaped particles are $\mathrm{CaMgSn}$ phase.

The microstructures and the corresponding grain size distributions of the annealed alloys are presented in Figure 6. For Ca modification, there exists a distinct grain refinement from $\sim 4.3 \mu \mathrm{m}$ to $\sim 3.0 \mu \mathrm{m}$, which is mainly due to the restraining effect on the growth of grains from precipitated particles [14,15]. In terms of texture, alloys displayed typical basal textures, while the texture intensity was apparently weakened by the addition of Ca. Previous studies have reported that coarse particles larger than $1 \mu \mathrm{m}$ in size can trigger the particle stimulation nucleation (PSN) mechanism, reduce the orientation correlation between recrystallization grains and present grains, and thus weaken the texture [16-18]. It is noteworthy that Ca-modified alloys contain particles larger than $1 \mu \mathrm{m}$ in size, and the basal poles of recrystallized grains disperse away from the normal direction more so than those of substructured and deformed grains (Figure 7). Determining PSN mechanism is the key factor to weaken texture [19].
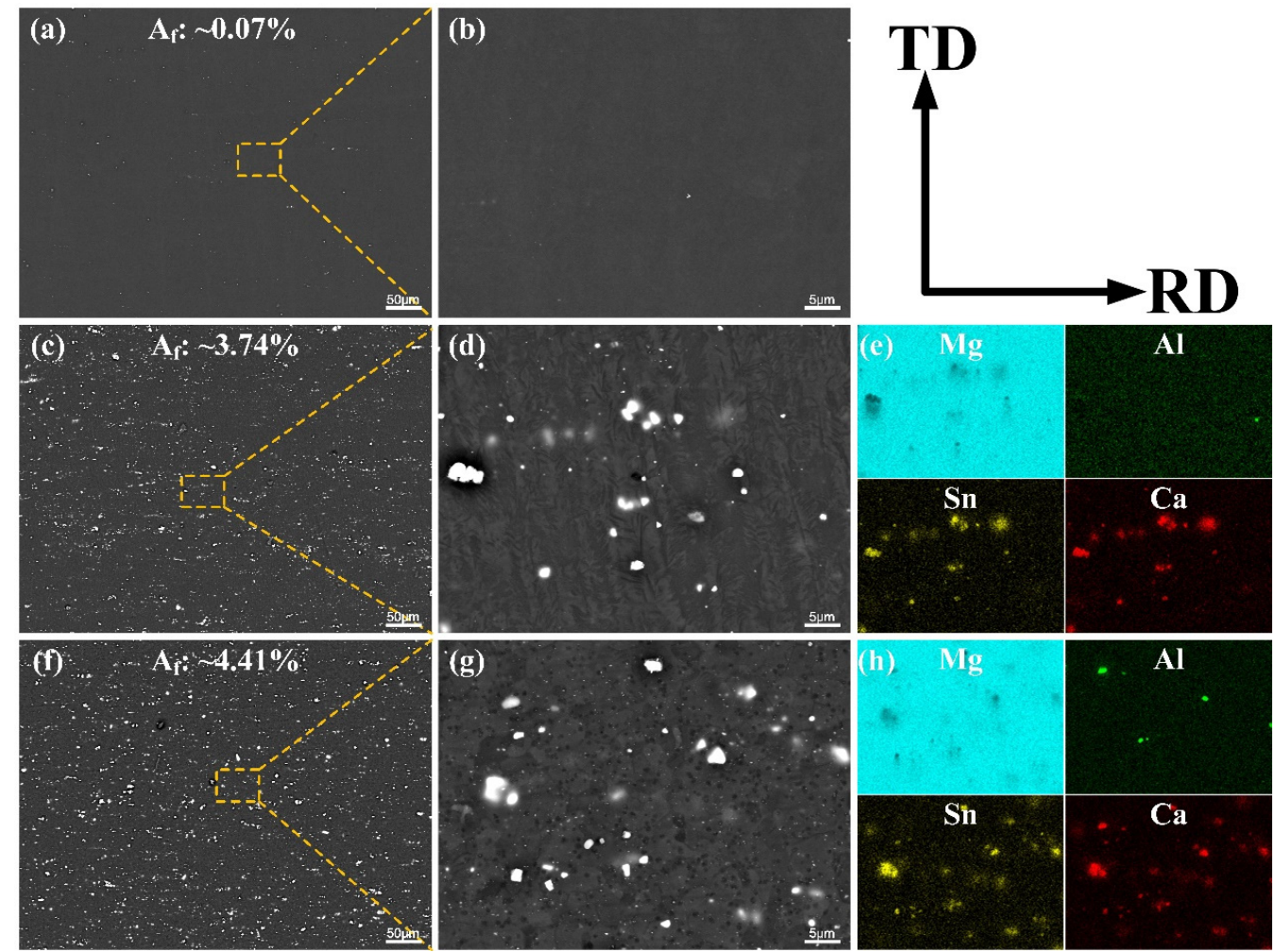

Figure 3. The backscattered electron SEM micrographs of (a,b) AT21, (c,d) ATX2103 and (f,g) ATX2105 alloys; EDS micrographs of (e) ATX2103 and (h) ATX2105 alloys. 

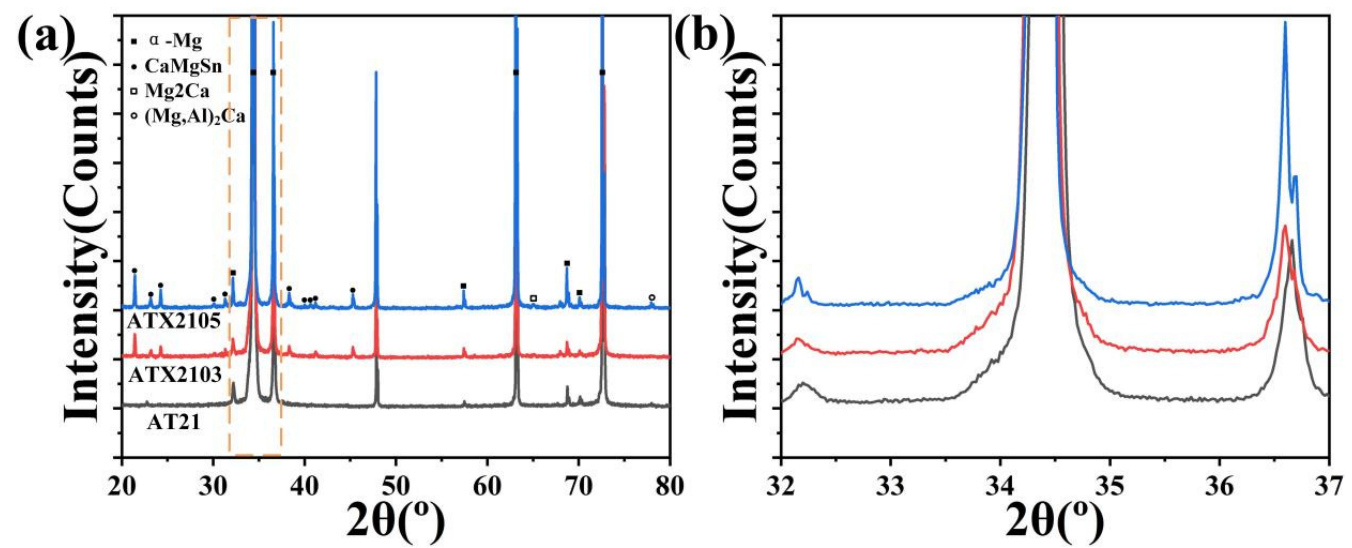

Figure 4. (a) The XRD patterns of the AT21, ATX2103 and ATX2105 samples, and (b) the enlarged section of the XRD patterns.
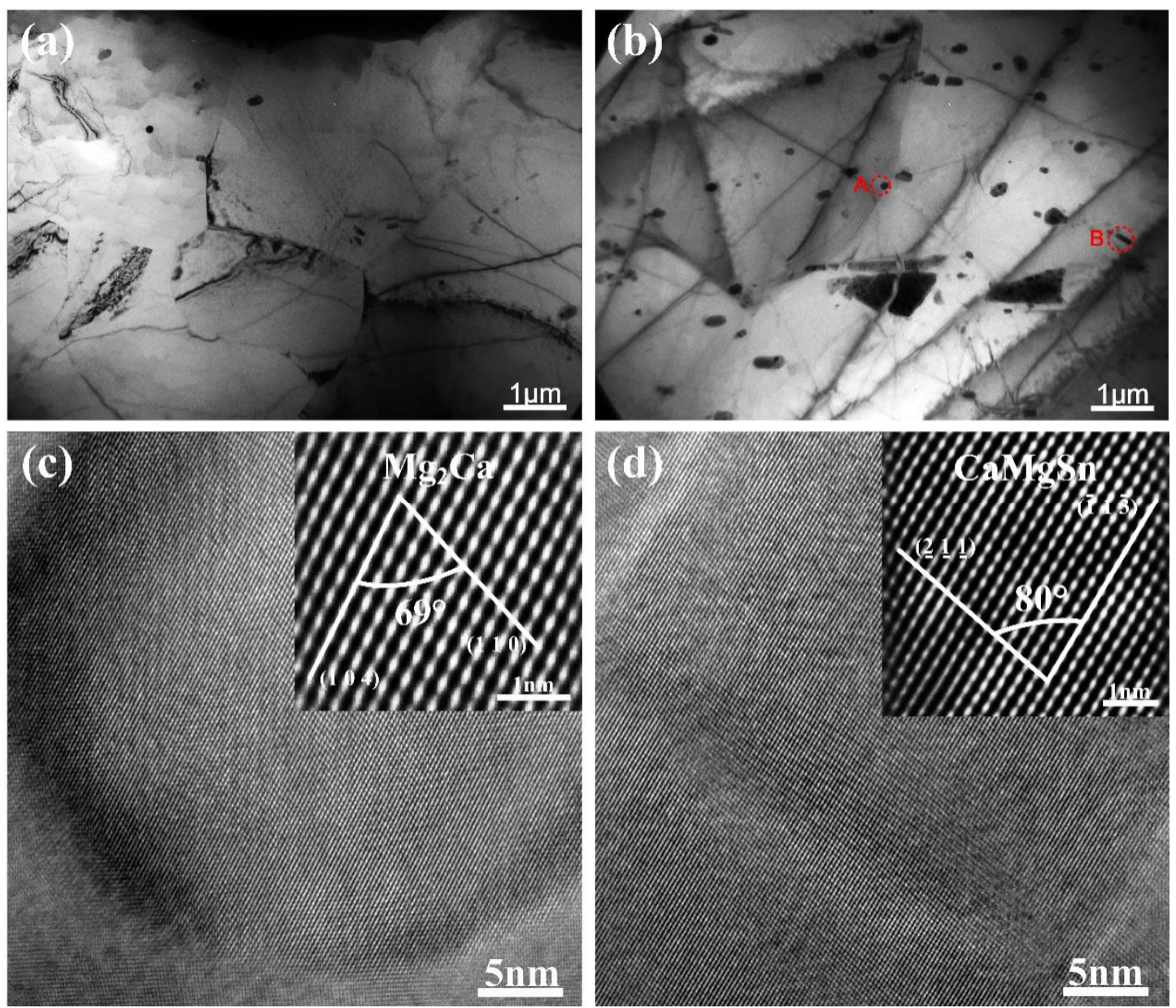

Figure 5. TEM micrographs of (a) ATX2103 and (b) ATX2105; the HRTEM micrograph of (c) particle A and (d) particle B. 

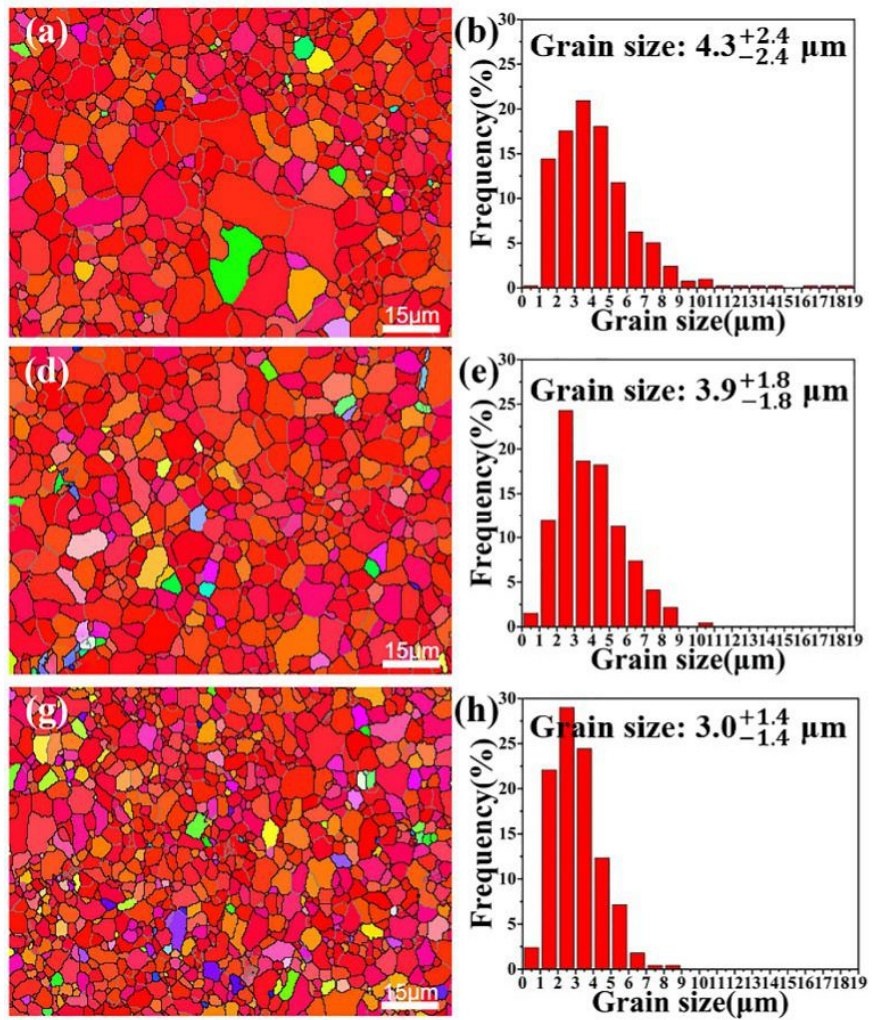

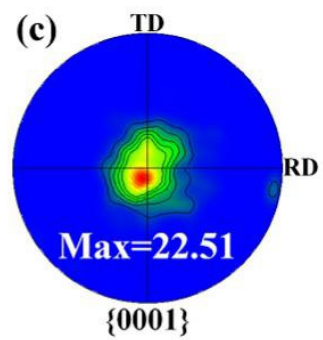

(f)
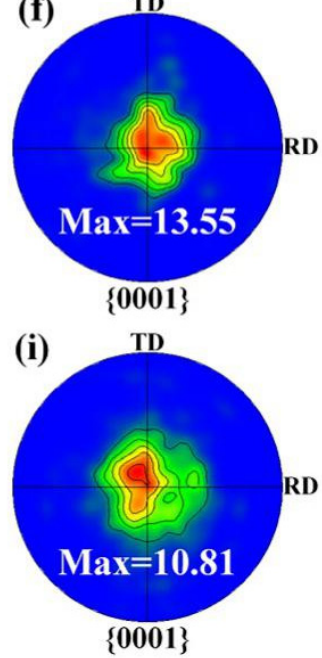

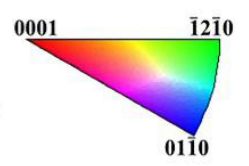

TD

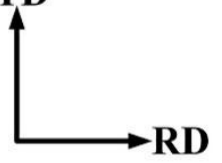

$\underline{\text { Min }} \underline{\text { Max }}$

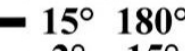

$-2^{\circ} 15^{\circ}$

Max

Figure 6. Inverse pole figure (IPF) maps with corresponding grain size distributions and $\{0001\}$ pole figures of (a-c) AT21, (d-f) ATX2103 and (g-i) ATX2105 alloys.
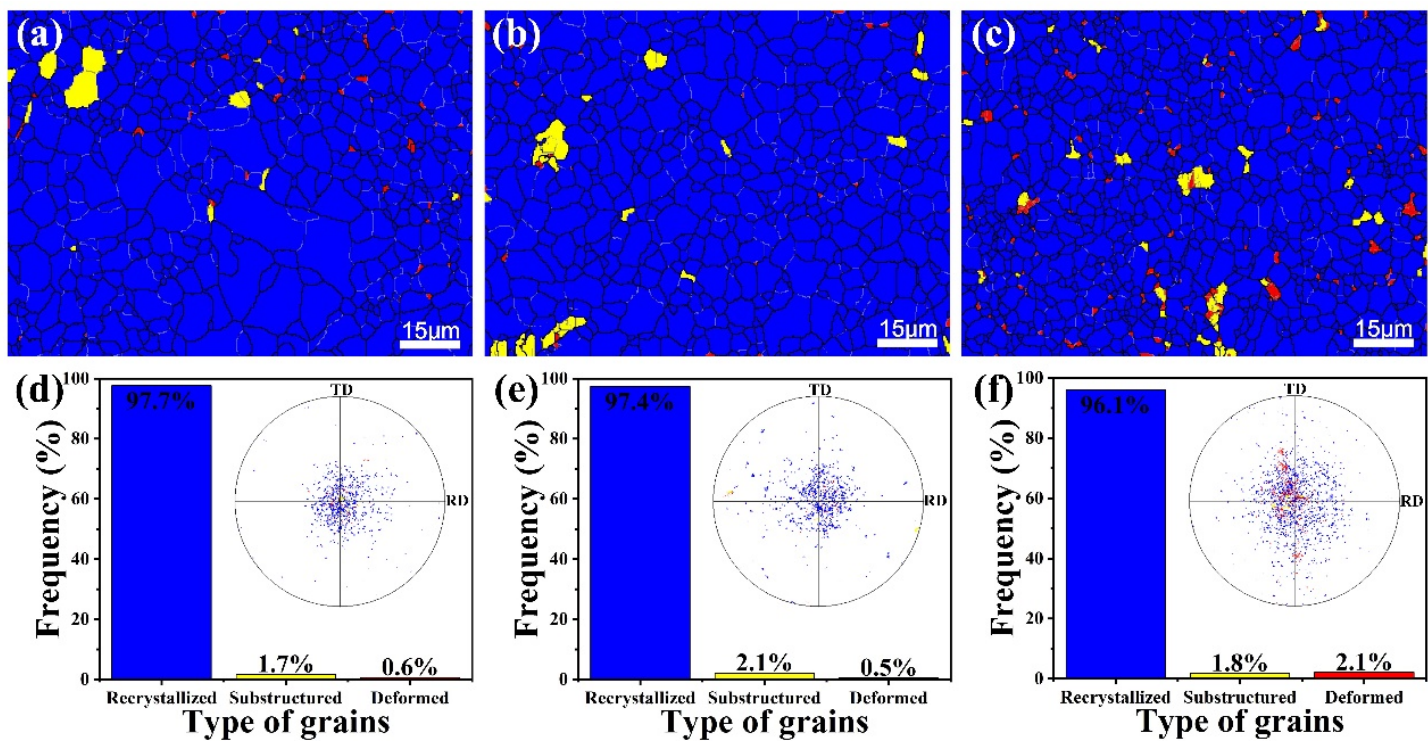

Figure 7. Different types of grains of (a) AT21, (b) ATX2103 and (c) ATX2105 alloys; (d-f) frequency and corresponding (0001) pole figures of the different types of grains shown in $(\mathbf{a}-\mathbf{c})$.

\subsection{Mechanical Properties}

Tensile engineering stress-strain curves for AT system alloys stretching along the RD, $45^{\circ}$, and TD, respectively, are revealed in Figure $8 \mathrm{a}-\mathrm{c}$, and related YS, UTS and EL are presented in Table 2. As is observed in Figure 8, both the strength and the EL increase monotonously with increasing of Ca content. And ATX2105 possesses the best tensile properties with a YS of $\sim 226.0 \mathrm{MPa}$, an UTS of $\sim 282.4 \mathrm{MPa}$ and an EL of $\sim 20.2 \%$ when tensiled along RD. It is evident that all samples display tensile property anisotropy. The 
minimum and maximum YS differences of AT21, ATX2103 and ATX2105 are 34.1, 29.8 and 17.6 $\mathrm{MPa}$, respectively, which indicates that the anisotropy becomes weaker with increasing of Ca content.
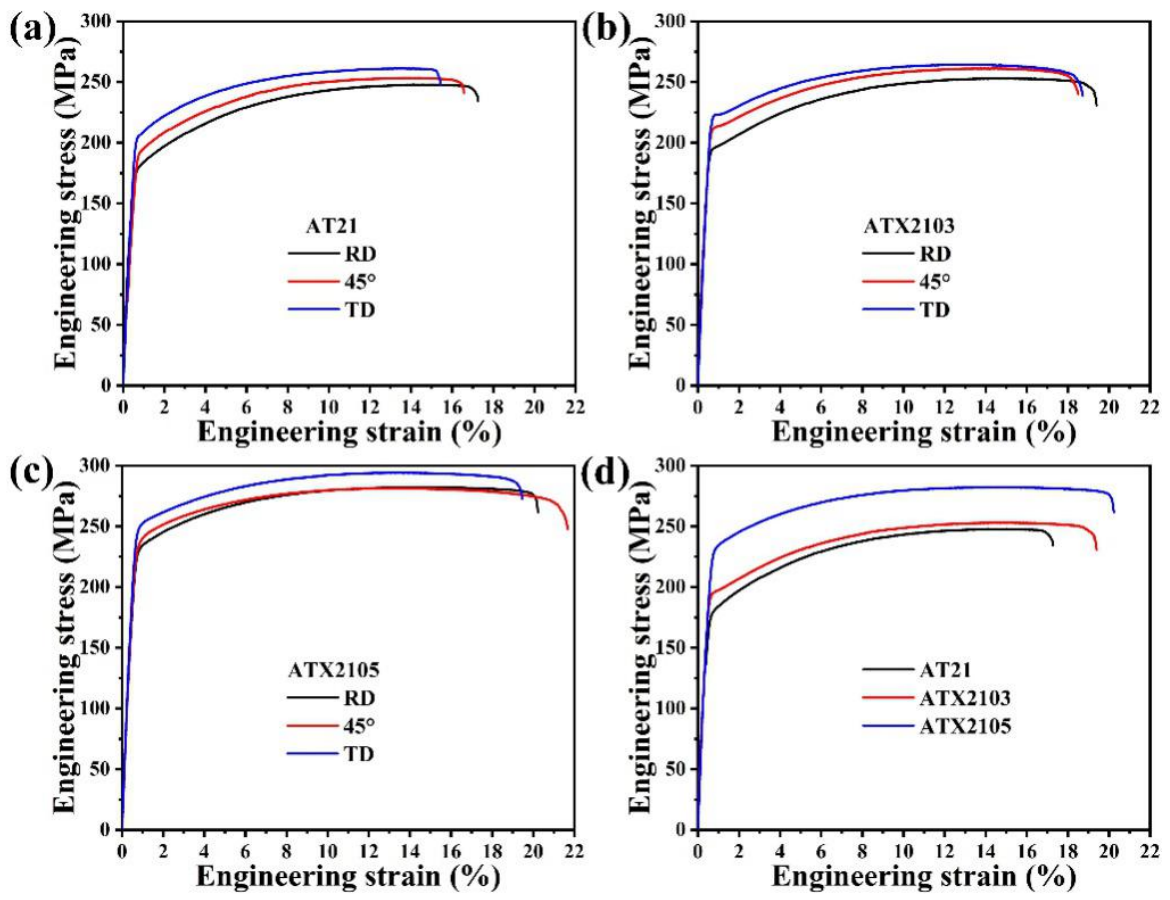

Figure 8. Engineering stress-strain curves of (a) AT21, (b) ATX2103 and (c) ATX2105; (d) the comparison of tensile properties of the samples tensiled along RD.

Table 2. Tensile properties of Mg-2.0Al-0.8Sn-xCa ( $x=0,0.3$ and 0.5 wt. $\%)$ alloys.

\begin{tabular}{ccccc}
\hline & & YS (MPa) & UTS (MPa) & EL (\%) \\
\hline \multirow{3}{*}{ AT21 } & RD & $171.0_{-0.4}^{+3.4}$ & $248.0_{-3.6}^{+0.3}$ & $17.3_{-2.3}^{+1.4}$ \\
& $45^{\circ}$ & $193.5_{-2.7}^{+2.6}$ & $253.4_{-2.1}^{+1.4}$ & $16.6_{-2.2}^{+1.9}$ \\
& TD & $205.1_{-3.5}^{+2.1}$ & $261.3_{-2.2}^{+3.1}$ & $15.4_{-1.3}^{+1.2}$ \\
\hline \multirow{3}{*}{ ATX2103 } & RD & $192.4_{-1.8}^{+2.2}$ & $253.1_{-2.7}^{+1.1}$ & $19.4_{-1.2}^{+1.1}$ \\
& $45^{\circ}$ & $211.0_{-2.4}^{+3.2}$ & $261.3_{-1.3}^{+2.2}$ & $18.5_{-1.2}^{+2.3}$ \\
& TD & $222.2_{-1.8}^{+2.1}$ & $264.4_{-1.2}^{+3.0}$ & $18.7_{-0.7}^{+0.2}$ \\
\hline \multirow{2}{*}{ ATX2105 } & RD & $226.0_{-0.7}^{+2.1}$ & $282.4_{-1.9}^{+1.5}$ & $20.2_{-0.3}^{+0.4}$ \\
& $45^{\circ}$ & $230.0_{-1.6}^{+2.0}$ & $281.5_{-1.8}^{+1.1}$ & $21.7_{-1.6}^{+0.7}$ \\
& TD & $243.8_{-1.0}^{+1.3}$ & $294.3_{-1.2}^{+1.6}$ & $19.5_{-0.4}^{+1.4}$ \\
\hline
\end{tabular}

Figure 9 shows the Schmid factor (SF) distributions of the $\{0001\}\langle 110\rangle$ slip system of all sheets along the RD and TD. Usually, the SF closely related to the grain orientation, and the larger the SF, the more favorable the orientation is for basal slip [20]. With the increase of Ca content, SF obviously increases, and the difference of SFs along different directions becomes smaller. This indicates that the addition of Ca promotes the basal slip and decreases the difference of activated slips for different directions, resulting in the higher ductility and weaker anisotropy of the Ca modified samples [21]. 

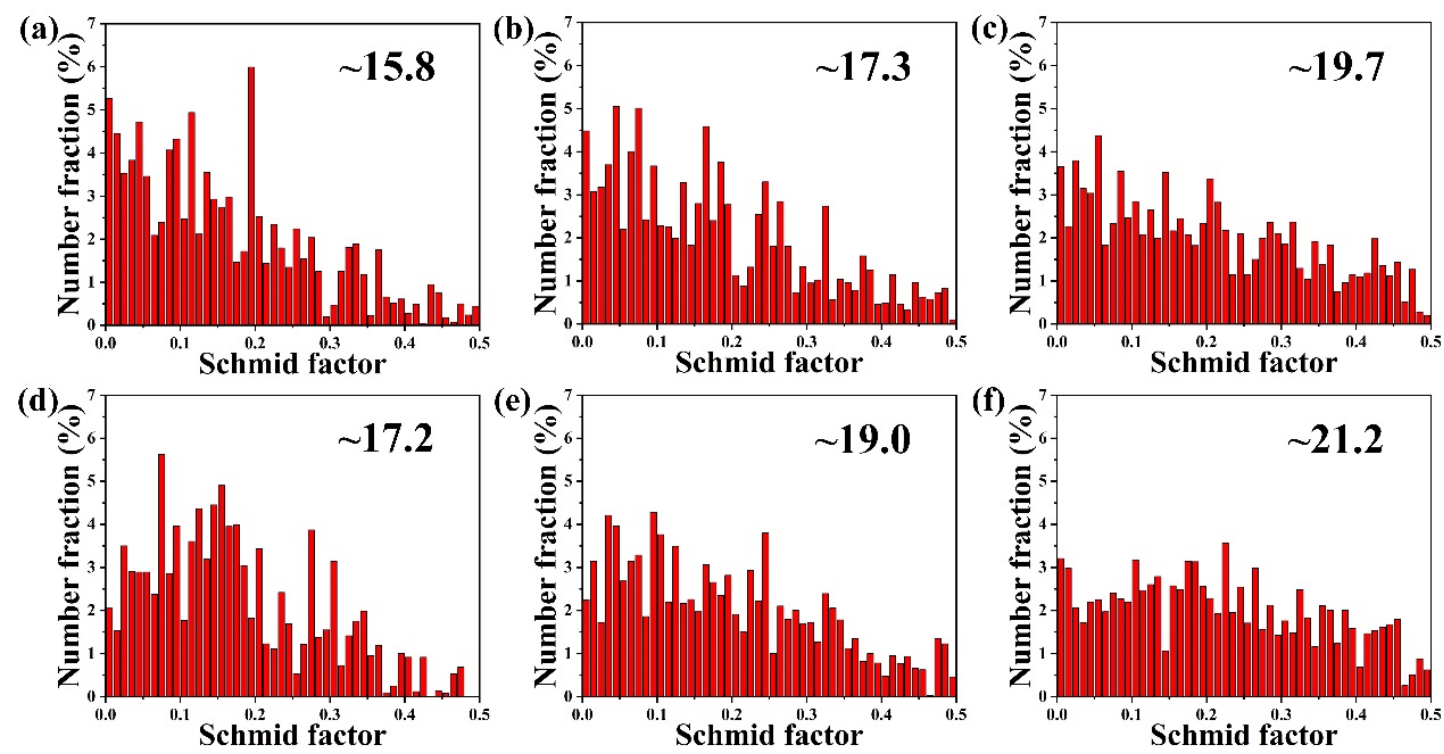

Figure 9. Schmid factor distribution maps based on $\{0001\}\langle 110\rangle$ slip system for RD of (a) AT21, (b) ATX2103 and (c) ATX2105, and for TD of (d) AT21, (e) ATX2103 and (f) ATX2105, respectively.

The YSs of all samples result from the synergetic role of fine grains, tiny precipitates, solute atoms, and residual dislocation density [22]. The contribution of fine grains $\left(\sigma_{\text {grain }}\right)$ can be determined by the Hall-Petch relationship [23]:

$$
\sigma_{\text {grain }}=k d^{-\frac{1}{2}}
$$

where $k$ is the Hall-Petch coefficient of $290 \mathrm{MPa} \mu \mathrm{m}^{1 / 2}$ and $\mathrm{d}$ is the average grain size [24]. On the basis of the measured average grain sizes of the alloys, the fine-grain contributions to the YSs are $139.8 \mathrm{MPa}, \sim 146.8 \mathrm{MPa}$ and $\sim 167.4 \mathrm{MPa}$.

Precipitation strengthening $\left(\sigma_{p}\right)$ can be evaluated by the Orowan looping mechanism. Since there is almost no second phase in AT21, precipitation strengthening is considered to be the only strengthening mechanism of Ca-containing samples. In addition, the increments in YS due to tiny precipitates strengthening are expressed as [25]:

$$
\sigma_{p}=M \frac{G b}{2 \pi \sqrt{1-v}\left(\frac{0.953}{\sqrt{f}}-1\right) d_{t}} \ln \frac{d_{t}}{b}
$$

where $M, G, b$ and $v$ are the Taylor factor, shear modulus, Burgers vector and Poisson's ratio (3.06 [26]), $1.66 \times 10^{4} \mathrm{MPa}$ [26], $3.2 \times 10^{-10} \mathrm{~m} \mathrm{[26]} \mathrm{and} 0.35$ [26] for Mg), and $d_{t}$ and $f$ are the mean diameter and volume fraction of precipitates (estimated to be $127 \mathrm{~nm}$ and $0.4 \times 10^{-2}$ for ATX2103, $145 \mathrm{~nm}$ and $1.4 \times 10^{-2}$ for ATX2105). According to the equation, a smaller particle size and a higher volume fraction can lead to a more significant strengthening effect on alloys. Additionally, the calculation contributions of precipitation strengthening in both alloys are $10.7 \mathrm{MPa}$ and $\sim 19.2 \mathrm{MPa}$.

In the studied alloys, $\mathrm{Al}, \mathrm{Sn}$, and $\mathrm{Ca}$ atoms may have a solid solution strengthening effect. However, owing to the similar atomic radius of $\mathrm{Sn}$ and $\mathrm{Mg}$ atoms, the solid solution strengthening effect of Sn can be negligible [22]. It has been reported that in Sn-containing $\mathrm{Mg}$ alloys, Ca formed the second phase, causing the solid solution strengthening effect of $\mathrm{Ca}$ to be weakened $[27,28]$. The XRD pattern between $32^{\circ}$ and $37^{\circ}$ (Figure $4 \mathrm{~b}$ ) further shows that the $\alpha-\mathrm{Mg}$ diffraction peaks have almost no angular shift with increasing of $\mathrm{Ca}$ content, indicating that the solid solution strengthening effect of $\mathrm{Ca}$ can also be ignored in 
this alloy system $[29,30]$. Therefore, the strengthening contribution from solute atoms can be estimated by the following formula [31]:

$$
\sigma_{s S}=\sigma_{A l}=k_{A l}^{1 / n} C_{A l}
$$

where $n$ is a constant of 2/3 [4], $k_{A l}$ is the constant for solute $\mathrm{Al}\left(196 \mathrm{MPa}(\mathrm{at.} \%)^{-2 / 3}\right.$ [22]), $C_{A l}$ is the concentration of solute $\mathrm{Al}$, which is $1.82 \mathrm{at} . \%$ of the three alloys, and the calculated value is $\sim 13.6 \mathrm{MPa}$.

The dislocation strengthening depends on the dislocation density. The geometrically necessary dislocation (GND) density and the hardening contribution can be estimated by the equations as follow [27,32]:

$$
\begin{gathered}
\rho_{G N D}=\frac{2 \theta}{\mu b} \\
\sigma_{D}=M \alpha G b \sqrt{\rho_{G N D}}
\end{gathered}
$$

where $\theta$ is the average misorientation, obtained from the Kernel average misorientation (KAM) dates (Figure 10); $\mu$ is the kernel size of $0.7 \mu \mathrm{m}$ in our work. The predicted results of the dislocation strengthening are thus $\sim 23.2 \mathrm{MPa}, \sim 24.8 \mathrm{MPa}$ and $\sim 25.8 \mathrm{MPa}$.
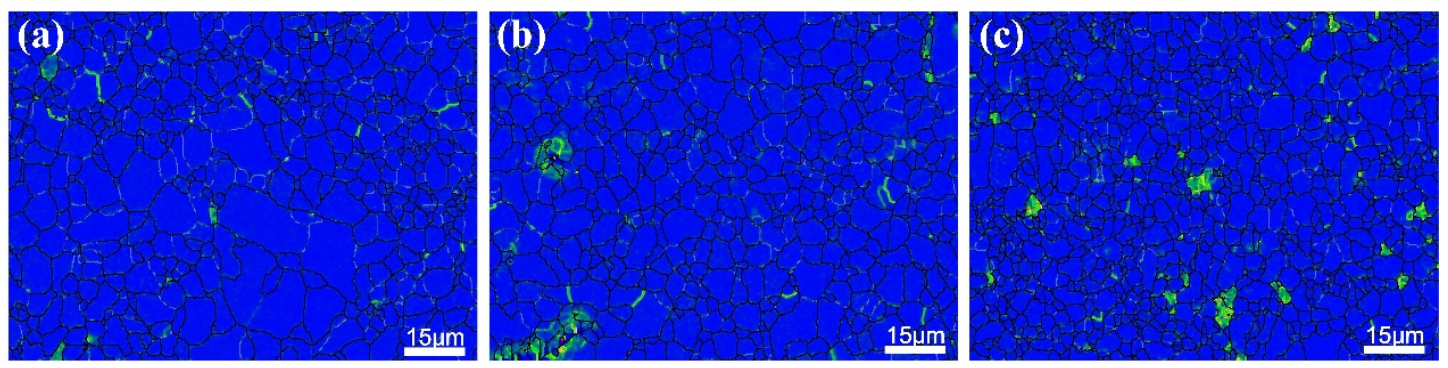

Figure 10. KAM results of (a) AT21, (b) ATX2103 and (c) ATX2105, respectively.

The calculated contributions of various strengthening mechanisms are included in Table 3. It can be seen that the calculated YSs are close to the measured YSs, indicating that the calculated values are accurate. The increase in YS under the addition of Ca may be thanks to the improved grain refinement, precipitation and dislocation strengthening effects.

Table 3. Contributions of various strengthening mechanism into the YS of AT21, ATX2103 and ATX2105 alloys.

\begin{tabular}{cccccccc}
\hline $\begin{array}{c}\text { Nominal } \\
\text { Composition }\end{array}$ & $\sigma_{\text {grain }} / \mathbf{M P a}$ & $\sigma_{p} / \mathbf{M P a}$ & $\sigma_{s s} / \mathbf{M P a}$ & $\sigma_{D} / \mathbf{M P a}$ & $\begin{array}{c}\text { Calculated } \\
\text { YS/MPa }\end{array}$ & $\begin{array}{c}\text { Measured } \\
\text { YS/MPa }\end{array}$ & Deviation/MPa \\
\hline AT21 & 139.8 & 0 & 13.6 & 23.2 & 176.6 & 171.0 & -5.5 \\
ATX2103 & 146.8 & 10.7 & 13.6 & 24.8 & 195.6 & 192.4 & -3.2 \\
ATX2105 & 167.4 & 19.2 & 13.6 & 25.8 & 226.0 & 226.0 & 0 \\
\hline
\end{tabular}

\section{Conclusions}

(1) With the addition of Ca in Mg-2.0Al-0.8Sn alloy from $0.0 \mathrm{wt} . \%$ to $0.5 \mathrm{wt} . \%$, the strength, ductility and isotropy of the alloys increase simultaneously. In addition, the ATX2105 alloy shows the best tensile properties with a YS of $\sim 226.0 \mathrm{MPa}$, a UTS of $\sim 282.4 \mathrm{MPa}$ and an EL of $\sim 20.2 \%$ along RD at room temperature.

(2) The second phases of the Ca-modified alloys are $\mathrm{CaMgSn},(\mathrm{Mg}, \mathrm{Al})_{2} \mathrm{Ca}$ phase and tiny $\mathrm{Mg}_{2} \mathrm{Ca}$ phase. However, when the Ca content is only $0.3 \mathrm{wt} . \%$, there is only a small amount of $(\mathrm{Mg}, \mathrm{Al})_{2} \mathrm{Ca}$ and $\mathrm{Mg}_{2} \mathrm{Ca}$. The AT21 alloy basically has no second phase.

(3) The enhancement of ductility and anisotropy via (0.0-0.5 wt.\%) Ca addition is mainly attributed to the texture modification, which promotes the basal slip and decreases the differences between activated slips for different directions. 
(4) The increase in YS under the addition of Ca originates from the synergetic effect of finer grain size, more tiny precipitates and residual dislocation density.

Author Contributions: Conceptualization, Y.M.; Data curation, Z.L.; Formal analysis, Y.M. and P.M.; Funding acquisition, C.W. and Z.L.; Investigation, Y.M.; Methodology, H.D. and Z.L.; Resources, C.W.; Validation, P.M.; Visualization, H.D.; Writing—original draft, Y.M.; Writing—review \& editing, M.W. and Z.L. All authors have read and agreed to the published version of the manuscript.

Funding: This work was financially supported by the National Key Research and Development Program of China (2020YFF0304103), the National Natural Science Foundation of China (U19A2084) and the Project of Jilin Province Science and Technology Department (20200401030GX). The authors would like to acknowledge the support from Jilin University Micro Analysis Centre for the experimental equipment.

Institutional Review Board Statement: Not applicable.

Informed Consent Statement: Not applicable.

Data Availability Statement: Data sharing not applicable. No new data were created or analyzed in this study. Data sharing is not applicable to this article.

Conflicts of Interest: The authors declare no conflict of interest.

\section{References}

1. Barrett, C.D.; Imandoust, A.; Oppedal, A.L.; Inal, K.; Tschopp, M.A.; El Kadiri, H. Effect of grain boundaries on texture formation during dynamic recrystallization of magnesium alloys. Acta Mater. 2017, 128, 270-283. [CrossRef]

2. Beausir, B.; Biswas, S.; Kim, D.I.; Tóth, L.S.; Suwas, S. Analysis of microstructure and texture evolution in pure magnesium during symmetric and asymmetric rolling. Acta Mater. 2009, 57, 5061-5077. [CrossRef]

3. Gong, X.; Kang, S.B.; Cho, J.H.; Li, S. Effect of annealing on microstructure and mechanical properties of ZK60 magnesium alloy sheets processed by twin-roll cast and differential speed rolling. Mater. Charact. 2014, 97, 183-188. [CrossRef]

4. Xu, H.; Guo, Z.P.; Zhang, P.Y.; Zhou, Y.; Ma, P.K. Influence of Texture on the Mechanical Properties of a Mg-6Al-1Zn-0.9Sn Alloy Processed by ECAP. Materials 2021, 14, 2664. [CrossRef]

5. Liu, X.; Qiao, X.; Li, Z.; Zheng, M. High strength and excellent ductility of dilute Mg-0.68Al-0.32Ca-0.50Mn (wt\%) extrusion alloy obtained by T6 treatment. Mater. Charact. 2020, 162. [CrossRef]

6. Wang, H.-Y.; Zhang, N.; Wang, C.; Jiang, Q.-C. First-principles study of the generalized stacking fault energy in Mg-3Al-3Sn alloy. Scr. Mater. 2011, 65, 723-726. [CrossRef]

7. Kabir, A.S.H.; Sanjari, M.; Su, J.; Jung, I.-H.; Yue, S. Effect of strain-induced precipitation on dynamic recrystallization in Mg-Al-Sn alloys. Mater. Sci. Eng. A 2014, 616, 252-259. [CrossRef]

8. She, J.; Pan, F.; Zhang, J.; Tang, A.; Luo, S.; Yu, Z.; Song, K.; Rashad, M. Microstructure and mechanical properties of Mg-Al-Sn extruded alloys. J. Alloys Compd. 2016, 657, 893-905. [CrossRef]

9. Zhang, A.; Kang, R.; Wu, L.; Pan, H.; Xie, H.; Huang, Q.; Liu, Y.; Ai, Z.; Ma, L.; Ren, Y.; et al. A new rare-earth-free Mg-Sn-Ca-Mn wrought alloy with ultra-high strength and good ductility. Mater. Sci. Eng. A 2019, 754, 269-274. [CrossRef]

10. Zhou, M.; Huang, X.; Morisada, Y.; Fujii, H.; Chino, Y. Effects of Ca and Sr additions on microstructure, mechanical properties, and ignition temperature of hot-rolled Mg-Zn alloy. Mater. Sci. Eng. A 2020, 769. [CrossRef]

11. Li, Z.T.; Zhang, X.D.; Zheng, M.Y.; Qiao, X.G.; Wu, K.; Xu, C.; Kamado, S. Effect of Ca/Al ratio on microstructure and mechanical properties of Mg-Al-Ca-Mn alloys. Mater. Sci. Eng. A 2017, 682, 423-432. [CrossRef]

12. Qudong, W.; Wenzhou, C.; Xiaoqin, Z.; Yizhen, L.; Wenjiang, D.; Yanping, Z.; Xiaoping, X.; Mabuchi, M. Effects of Ca addition on the microstructure and mechanical properties of AZ91magnesium alloy. J. Mater. Sci. 2001, 36, 3035-3040. [CrossRef]

13. Pan, H.; Qin, G.; Huang, Y.; Ren, Y.; Sha, X.; Han, X.; Liu, Z.-Q.; Li, C.; Wu, X.; Chen, H.; et al. Development of low-alloyed and rare-earth-free magnesium alloys having ultra-high strength. Acta Mater. 2018, 149, 350-363. [CrossRef]

14. Zhang, B.; Wang, Y.; Geng, L.; Lu, C. Effects of calcium on texture and mechanical properties of hot-extruded Mg-Zn-Ca alloys. Mater. Sci. Eng. A 2012, 539, 56-60. [CrossRef]

15. Zareian, Z.; Emamy, M.; Malekan, M.; Mirzadeh, H.; Kim, W.J.; Bahmani, A. Tailoring the mechanical properties of Mg-Zn magnesium alloy by calcium addition and hot extrusion process. Mater. Sci. Eng. A 2020, 774, 138929. [CrossRef]

16. Zhong, L.; Wang, Y.; Dou, Y. On the improved tensile strength and ductility of Mg-Sn-Zn-Mn alloy processed by aging prior to extrusion. J. Magn. Alloys 2019, 7, 637-647. [CrossRef]

17. Robson, J.D.; Henry, D.T.; Davis, B. Particle effects on recrystallization in magnesium-manganese alloys: Particle-stimulated nucleation. Acta Mater. 2009, 57, 2739-2747. [CrossRef]

18. Lotfpour, M.; Bahmani, A.; Mirzadeh, H.; Emamy, M.; Malekan, M.; Kim, W.J.; Taghizadeh, M.; Afsharnaderi, A. Effect of microalloying by $\mathrm{Ca}$ on the microstructure and mechanical properties of as-cast and wrought $\mathrm{Mg}-\mathrm{Mg}_{2} \mathrm{Si}$ composites. Mater. Sci. Eng. A 2021, 820, 141574. [CrossRef] 
19. Chai, Y.; Jiang, B.; Song, J.; Wang, Q.; Gao, H.; Liu, B.; Huang, G.; Zhang, D.; Pan, F. Improvement of mechanical properties and reduction of yield asymmetry of extruded $\mathrm{Mg}-\mathrm{Sn}-\mathrm{Zn}$ alloy through Ca addition. J. Alloys Compd. 2019, 782, 1076-1086. [CrossRef]

20. Xiong, J.; Chen, Z.; Yi, L.; Hu, S.; Chen, T.; Liu, C. Microstructure and mechanical properties of annealed Mg- $0.6 \mathrm{wt} \% \mathrm{Zr}$ sheets by unidirectional and cross rolling. Mater. Sci. Eng. A 2014, 590, 60-65. [CrossRef]

21. Wu, J.; Jin, L.; Dong, J.; Wang, F.; Dong, S. The texture and its optimization in magnesium alloy. J. Mater. Sci. Technol. 2020, 42, 175-189. [CrossRef]

22. Ma, C.-Y.; Xia, N.; Wang, C.; Li, M.-X.; Hua, Z.-M.; Ren, M.-W.; Wang, H.-Y. A novel Mg-5Al-2Zn-2Sn alloy with high strengthductility synergy fabricated via simple hot rolling and annealing treatment. J. Alloys Compd. 2021, 869. [CrossRef]

23. Zhang, S.Y.; Wang, C.; Zhao, L.Q.; Ma, P.K.; Song, J.W.; Xu, J.; Cheng, X.M.; Wang, H.Y. Superplastic Deformation Behavior of Rolled Mg-8Al-2Sn and Mg-8Al-1Sn-1Zn Alloys at High Temperatures. Materials 2020, 13, 1074. [CrossRef]

24. Kim, W.J.; Jeong, H.G.; Jeong, H.T. Achieving high strength and high ductility in magnesium alloys using severe plastic deformation combined with low-temperature aging. Scr. Mater. 2009, 61, 1040-1043. [CrossRef]

25. Wang, P.-Y.; Wang, B.-Y.; Wang, C.; Wang, J.-G.; Ma, C.-Y.; Li, J.-S.; Zha, M.; Wang, H.-Y. Design of multicomponent Mg-Al-ZnSn-Bi alloys with refined microstructure and enhanced tensile properties. Mater. Sci. Eng. A 2020, 791, 139696. [CrossRef]

26. Nie, J.F. Effects of precipitate shape and orientation on dispersion strengthening in magnesium alloys. Scr. Mater. 2003, 48, 1009-1015. [CrossRef]

27. Pan, H.; Kang, R.; Li, J.; Xie, H.; Zeng, Z.; Huang, Q.; Yang, C.; Ren, Y.; Qin, G. Mechanistic investigation of a low-alloy Mg-Ca-based extrusion alloy with high strength-ductility synergy. Acta Mater. 2020, 186, 278-290. [CrossRef]

28. Li, Z.; Miao, Y.; Liu, F.; Ma, P.; Wang, H. Enhanced precipitation strengthening of Mg-Al-Sn-Ca alloy by multidirectional rolling. Materialia 2021, 19, 101185. [CrossRef]

29. Wang, P.-Y.; Wang, J.-G.; Jia, H.-L.; Wang, C.; Li, J.-S.; Hu, Z.-T.; Zha, M.; Wang, H.-Y. Development of high strength and formability Mg-6Zn-0.2Ca alloy via multi-pass warm rolling and aging treatment. Mater. Sci. Eng. A 2021, 819, 141452. [CrossRef]

30. Sun, W.T.; Qiao, X.G.; Zheng, M.Y.; Xu, C.; Kamado, S.; Zhao, X.J.; Chen, H.W.; Gao, N.; Starink, M.J. Altered ageing behaviour of a nanostructured Mg-8.2Gd-3.8Y-1.0Zn-0.4Zr alloy processed by high pressure torsion. Acta Mater. 2018, 151, 260-270. [CrossRef]

31. Gao, L.; Chen, R.S.; Han, E.H. Effects of rare-earth elements Gd and Y on the solid solution strengthening of Mg alloys. J. Alloys Compd. 2009, 481, 379-384. [CrossRef]

32. Ma, X.; Huang, C.; Moering, J.; Ruppert, M.; Höppel, H.W.; Göken, M.; Narayan, J.; Zhu, Y. Mechanical properties of copper/bronze laminates: Role of interfaces. Acta Mater. 2016, 116, 43-52. [CrossRef] 